\title{
Subependymal Pseudocyst
}

National Cancer Institute

\section{Source}

National Cancer Institute. Subependymal Pseudocyst. NCI Thesaurus. Code C117315.

Cerebral periventricular cyst located on the floor of the lateral cerebral ventricle, most commonly in the caudothalamic groove, and results from regression of the germinal matrix or as a sequela of a prior subependymal hemorrhage or germinal matrix infarct. 